\title{
PROBIOTICS AND HUMAN HEALTH: SYNOPTIC REVIEW
}

\section{Maity TK $^{1^{*}}$ and AK Misra ${ }^{1}$}

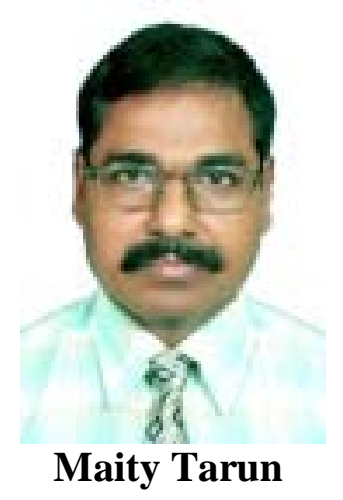

*Corresponding author email: maity.tk@gmail.com

${ }^{1}$ Department of Dairy Microbiology, Faculty of Dairy Technology, West Bengal University of Animal and Fisheries Sciences, Mohanpur Campus, District - Nadia, West Bengal-741252, India 


\section{ABSTRACT}

The development of probiotic, functional foods aims to "kill two birds with one stone," which is accomplished by providing a microbial stimulus to the host immune system by means of beneficial live microorganism cultures that are characteristic of the healthy, human gut microflora. Several probiotic preparations seem to have promise in prevention or treatment of various conditions. Probiotic bacteria reinforce the different lines of gut defense, which are immune exclusion, immune elimination, and immune regulation. They stimulate non-specific host resistance to microbial pathogens, thereby aiding in pathogen eradication. Best documented clinical application of probiotics is in the treatment of acute diarrhea. In humans, documented effects were reported for the alleviation of intestinal inflammation, normalization of gut mucosal dysfunction, and down-regulation of hypersensitivity reactions. The efficacy of probiotics in acute enteric infections and post-antibiotic syndromes is now established and there is emerging evidence for a role in alleviation of necrotizing enterocolitis, irritable bowel syndrome, and some forms of inflammatory bowel disease. Probiotics are gaining importance because of their innumerable benefits, e.g. treating lactose intolerance, hypercholesterol problem, cardiac diseases and managing cardiac problems like atherosclerosis and arteriosclerosis. However, adequate information by which the consumer and health professional can judge the efficacy and safety of retailed probiotics is lacking. Probiotic products have not been subjected to large-scale trials of efficacy that are used in the pharmaceutical industry. Without these trials and subsequent approval by fastidious regulatory agencies such as the FDA (USA), probiotics continue to languish in the self-care health market. However, the future is bright; enhanced understanding of the molecular details of host's microflora flora interactions within the gut promises to yield new therapeutic targets and the potential to move from "bugs to drugs". With the current focus on disease prevention and the quest for optimal health at all ages, the probiotics market potential is enormous. Health professionals are in an ideal position to help and guide their clients toward appropriate prophylactic and therapeutic uses of probiotics that deliver the desired beneficial health effects.

Key words: eubiosis, diarrhoea, ecosystem, inflammation 


\section{INTRODUCTION}

Probiotics have a long history of human use, and cultured dairy products, for example, are traditionally consumed in several parts of the world. The FAO/WHO defines probiotics as 'Live microorganisms which when administered in adequate amounts confer a health benefit on the host' [1]. The first recorded probiotic was fermented milk for human consumption. After that, probiotics became popular with animal nutrition. The role of fermented milk in human diet was known even in Vedic times. But, the scientific interest in this area boosted after the publication of the book entitled The Prolongation of Life [2] by Metchnikoff.

In this book, Metchnikoff suggested that people should consume fermented milk containing lactobacilli to prolong their lives. He argued that accelerated aging is because of autointoxication (chronic toxemia), which is due to the toxins produced by gut microflora. Bulgarian peasants who were subjected to his experiments on longevity had consumed large quantities of sour milk $\mathrm{He}$ concluded that the pathological reactions might be removed and life expectancy could be enhanced by implanting lactic acid bacteria from Bulgarian yogurt [2]. Since then, researchers started investigations relating to the role of lactic acid bacteria in human and animal health.

Across the globe, about 20 probiotic strains, singly or in combination, mainly Lactobacilli such as L. acidophilus, L. casei, L.reuterii and others; Bifidobacteria, safe spore forming lactic acid producing bacteria (such as Lactospore; Bacillus coagulans also known as Lactobacillus sporogenes), and a probiotic yeast culture Saccharomyces boulardii, are used in dietary supplements and functional foods or in mainstream food products. Contemporary interest in probiotics can be partially attributed to Metchnikoff's theory of longevity, which associated prolonged youth and a healthy old age, common in Balkan peasants of those times, with the use of cultured milks in their diet.

\section{SYNOPTIC REVIEW}

\section{Gut ecology and health applications of probiotic}

Humans cannot ever live free from intestinal bacteria. Colonization of the gut with microflora begins in the infant, shortly after birth. The micro-ecology of the human gastrointestinal tract is a complex one, generally involving two kinds of flora: Indigenous beneficial bacteria which have achieved a symbiotic relationship with the host through a long period of evolution and potentially pathogenic bacteria. An optimal "balance" in this microbial population is associated with good health in humans [3]. This balance of beneficial bacteria versus pathogenic bacteria is referred to as "eubiosis". For efficient digestion and maximum absorption of nutrients, it is essential that the right balance of microorganisms be maintained. This balance is often compromised during antibiotic therapy and the immune system is weakened by disease, stress or other factors. Evidence indicates that certain micro-organisms, particularly the lactic acid producing organisms that are natural inhabitants of the

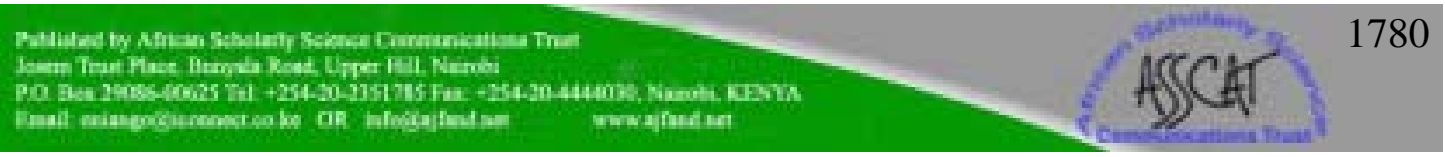


gastrointestinal tract, or "semi-residents" that help to restore the natural microecological balance, can facilitate a favorable microbial profile in the gut.

\section{Healthy gut microflora- the source of probiotics}

Microbial colonization begins after birth, and initially, facultative anaerobic strains dominate. Thereafter, lactic acid bacteria and coliforms become the predominant microorganisms of the gut microflora [4]. After weaning, the type of diet determines the relative distribution of bacterial species. Breast-feeding encourages the growth of bifidobacteria in the gut, whereas formula-fed infants have a more complex microflora that contains bifidobacteria, bacteroides, clostridia, and streptococci. After weaning, the composition of the microflora resembles that of the adult flora [5]. In the ileum, bacterial concentrations gradually increased to $\leq 10^{14}$ total bacterial cells of different culturable species. Several reports have indicated that 5 Genera account for most of the viable forms of anaerobic bacteria: Bacteroides, Eubacterium, Bifidobacterium, Peptostreptococcus, and Fusobacterium [4, 5].

Various facultative and aerobic organisms are also present in the colon. Most of these bacteria are hitherto uncharacterized because of the presence of non-culturable bacteria and the inaccuracy and insufficiency of the identification procedures available. The complex ecosystem of the adult intestinal microflora is estimated to harbor 500 different bacterial species. Some of these species are considered potentially harmful because of their abilities of toxin production, mucosal invasion, or activation of carcinogens and inflammatory responses [5]. The strains with healthpromoting properties principally include bifidobacteria and lactobacilli.

In infectious and inflammatory conditions, the balance of the gut micro-ecology is altered in such a way that the number of potentially pathogenic bacteria grows. Then healthy interaction between the host and microbe is disturbed such that an immune response may be induced by resident bacteria. Probiotics are beneficial bacteria that exist in the healthy gut microflora. The classification of a strain as probiotic requires that it's beneficial physiologic effects be proven scientifically, that the strain be of human origin, be safe for human use, be stable in acid and bile, and that it adhere to the intestinal mucosa [5]. The most frequently used genera fulfilling these criteria are Lactobacillus and Bifidobacterium.

\section{Composition of probiotics}

Probiotics can be bacteria, moulds, yeast. But most probiotics are bacteria. Among bacteria, lactic acid bacteria are more popular. Lactobacillus acidophilus, L. casei, L. lactis, L. helviticus, L. salivarius, L. plantrum, L. bulgaricus, L. rhamnosus, L. johnsonii, L. reuteri, L. fermentum, L. delbrueckii, Streptococcus thermophilus, Enterococcus faecium, E. faecalis, Bifidobacterium bifidum, B. breve, B. longum and Saccharomyces boulardii are commonly used bacterial probiotics (Table 1). A probiotic may be made out of a single bacterial strain or it may be a consortium as well. Probiotics can be in powder form, liquid form, gel, paste, granules or available in the form of capsules and sachets.

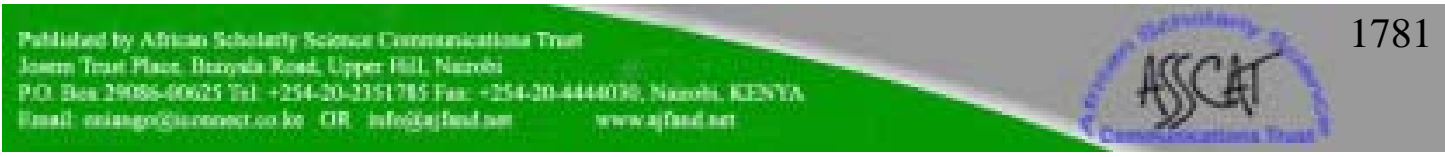




\section{Healthful role of probiotics}

\section{Anti-mutagenic effect}

Milk cultured with Lactobacilli strains have been shown to have anti-mutagenic effects in laboratory experiments including animal studies, reducing mutagenicity and chromosome damage by approximately $80 \%$ [6, 7]. One proposed mechanism thought to be able to explain the anti-mutagenic action of lactic acid bacteria, is due to their ability to bind with these heterocyclic primary amines produced from cooked meat [8]. Several laboratory studies have demonstrated that various species of lactic acid bacteria are capable of binding these mutagenic chemicals, even in human gastric juice, thus rendering them harmless [9]. Further experiments suggest that lactic acid bacteria may be capable of protecting against the mutagenic effect of other carcinogens as well.

\section{Cholesterol assimilation}

It is thought that the mechanisms by which lactic acid bacteria exert their effect on cholesterol is through bile acids. The liver uses cholesterol to produce bile acids, which are secreted into the small intestine, and then absorbed again and sent back to the liver. Whilst these bile acids are in the intestine however they can be broken down by certain kinds of bacteria that inhabit the gut [10]. This has been evidenced in animal studies which found that greater gut bacteria resulted in greater elimination of bile acids [11].If the intestinal bacteria are breaking down and thus inhibiting the reabsorption of bile salts, then they would not be able to be recycled. Therefore, livers cholesterol storage would begin to be reduced because it would be needed to synthesise new bile acids due to the lack of recycling [12]. Therefore it has been suggested that this effect could be increased if the gut were to be colonised with more of the bacterial types capable of breaking down the most bile, such as Lactobacillus acidophilus [13]. Because most of the cholesterol found in blood serum comes from the liver, this effect would inevitably help to lower serum cholesterol levels, thus decreasing the risk of heart disease. In 1979, the first trial to evaluate the effects of lactic acid bacteria on serum cholesterol levels in humans was conducted. Fifty four volunteers participated in a randomised cross over trial; the results of which revealed reductions of between 5-10\% in serum cholesterol levels after several weeks of moderate consumption of yoghurt fermented with Lactobacillus bulgaricus and $S$. thermophilus [14].

A Dutch trial involving 30 healthy men also found that consuming yoghurt fermented with L. acidophilus cultures for several weeks decreased both total and LDL cholesterol levels by 4.4 and $5.4 \%$ respectively compared with controls [14].Similar results were not obtained however, in a controlled trial lasting 6 weeks involving 78 healthy subjects, which found that consumption of yoghurt fermented with $L$. acidophilus had no significant effect on serum cholesterol levels at all [15]. Products of bacterial fermentation, specifically short-chain fatty acids, may inhibit cholesterol synthesis in the liver and/or cause the mobilization of plasma cholesterol to the liver [16]. Some gastrointestinal bacteria may also prevent cholesterol absorption by

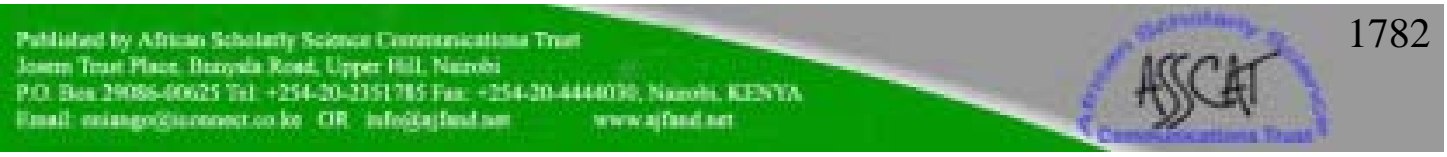


deconjugating bile salts that then affect cholesterol metabolism. Taranto et al. [17] reported that administration of Lactobacillus reuteri was effective in preventing hypercholesterolemia in mice. In addition, he observed a decrease in total cholesterol $(22 \%)$ and triglycerides (33\%), as well as a $17 \%$ increase in the ratio of HDL to LDL.

Several of these trials however failed to mention what concentration of bacteria was present in each product; thus it is not possible to know what dosage would be required to obtain these cholesterol-lowering results. Moreover, the subject in these studies had cholesterol levels that were either normal or relatively low, so it cannot be known how effective such treatments may be in subjects with high cholesterol. It may be reasonable to speculate that the cholesterol lowering effect may be more pronounced in hypercholesterolemic patients; however, at present there is no data to support this theory.

\section{Blood pressure}

It has been suggested that consumption of fermented milk may be beneficial to hypertensive patients, after feeding either fermented products or peptides isolated from fermented milk could lower blood pressure in hypertensive rats [18, 19]. In a placebo-controlled trial involving hypertensive patients, 8 weeks of consuming sour milk fermented by Lactobacillus helveticus and Saccharomyces cerevisiae resulted in significant reductions in both systolic and diastolic blood pressure [20]. Although the reductions in blood pressure seen in hypertensive patients consuming fermented milk products may not be significant enough to be used as a sole treatment for high blood pressure, these studies provide preliminary evidence to suggest that consumption of lactic acid bacteria fermented dairy foods along with a host of other functional foods known to have beneficial effects on blood pressure, could at least be incorporated into dietary strategies used to complement medical treatments for hypertensive patients. For the rest of us, it may simply aid in maintaining healthy blood pressure levels; thus acting as a preventative measure.

\section{Immune function IgA}

There is a significant body of evidence from clinical and laboratory investigations to suggest that consumption of lactic acid bacteria may have favourable effects on immune function. Antibodies such as Immunoglobulin A (IgA) are produced by plasma cells of the immune system and are involved in protecting the body from potentially harmful microbes. Secretory immunoglobulin A, (sIgA) is specifically found at the surface of the intestinal mucosa (the outer membrane layer coated in mucous that is exposed to the guts contents) and works by preventing pathogens from binding with and penetrating the gut wall. Lactobacillus casei, Lactobacillus acidophilus and yogurt have been shown to enhance the number of IgA-producing plasma cells in a dose-dependent manner as well as increasing sIgA levels in mice and humans [21]. 


\section{Phagocytosis}

Another beneficial mechanism that lactic acid bacteria may have on immune function is the ability to enhance a process known as phagocytosis, which is where certain types of white blood cells known as macrophages literally engulf and ingest invaders such as harmful bacteria and other disease causing microbes (pathogens); a process thought to be one of the bodies first lines of defence against harmful bacterial infections. Furthermore, Lactobacillus acidophilus and Bifidobacterium longum have been found to enhance phagocytic function of human macrophages in vitro [22]. While animal studies have demonstrated that L. acidophilus $L$. casei and Streptococcus thermophilus either enhanced or increased phagocytosis in the macrophages of rodents. In a double blind, placebo-controlled trial designed to determine the effects of lactic acid bacteria on immune function, 25 elderly volunteers were given either low fat milk or the same milk with added cultures of a strain of Bifidobacteria lactis called HN019. The results demonstrated that after 6 weeks, those who received the probiotic milk had significantly improved markers of natural immunity such as enhanced levels of interferon-alpha and increases in the phagocytic capacity of certain immune cells [23].

\section{Infections}

Ingestion of lactic acid bacteria has also been found to be beneficial in people infected with the bacterium Helicobacter pylori which is responsible for gastritis and peptic ulcers [24]. Various strains of lactic acid bacteria probiotics such as those isolated from yoghurt have been proven to reduce the growth of H.pylori in vitro [25]. In animal studies and human clinical trials, presumable by producing selectively antibacterial substances known as bacteriocins and by inhibiting binding ability [26, 27, 28]. Lactobacillus johnsonii is probably the most successful species of probiotic shown to reduce H.pylori infection. [29]. Further investigations in Switzerland have found that $L$. johnsonii probiotics are capable of producing a favourable affect on H.pylori induced gastritis in human subjects including a trial which found that 2 weeks of $L$. johnsonii consumption suppressed H.pylori infection regardless of whether it was combined with a standard medication used to treat $H$. pylori called omeprazole, or with a placebo [30].

Some strains of Lactobacillus and Bifidobacterium have been shown to exert bacteriostatic or bactericidal effects against $H$. pylori through the release of bacteriocins or organic acids in both in vitro and in vivo models [31]. Probiotics also have a possible role in stabilization of the gastric barrier function and decreasing mucosal inflammation in the gastric mucosa [31]. They recently conducted a systematic review of the clinical trials using probiotics in adults and children colonized with $H$. pylori and concluded that probiotics as a single therapy do not appear to eradicate $H$. pylori but may maintain lower levels of this pathogen [31]. The probiotic strains L. johnsonii [32], L. gasseri [33], L. casei [34] and Clostridium butyricum [35] appear to be most promising in reducing the density of colonization of $H$. pylori. When probiotics are administered in combination with antibiotics, probiotics may increase eradication rate and decrease adverse effects associated with antibiotic therapy [31]. 
Other investigations have found that the addition of probiotics to standard drug treatments can enhance their effectiveness or reduce the severity of the drug-related side effects [34, 36]. A trial involving 120-infected patients in Italy which found that patients given the conventional medical treatments (rabeprazole, clarithromycin and amoxicillin) had a $72 \%$ successful eradication of the infection after 1 week, whereas those given the same treatment plus L. acidophilus probiotics had an $88 \%$ rate of success [37]. In another study showed that the recommended first-line $H$. pylori eradication therapy has detrimental acute effects as well as minor long-term effects on the intestinal microbiota [38]. They suggested that oral probiotic supplementation during and 3 weeks after triple therapy may slightly diminish the microbial disturbances, since the degree of lactobacilli/enterococci alterations decreases and the amount of total aerobes increases. However, the probiotic combination appeared to result in only minor changes in the microbiota.

\section{Diarrhoea}

Diarrhoea is one of the most common causes of sickness in young children, often caused by rotavirus infections. It results in approximately 3 million doctors visits per year and contributes roughly $13 \%$ of hospitalizations among children under 5 [39].The results of randomized, double blind placebo-controlled trials have found that administration of probiotics containing Lactobacillus GG, Lactobacillus reuteri, $L$. acidophilus or L. acidophilus combined with L. bulgaris have proven effective in the treatment of diarrhoea in children between 1 month and 2.5 years old, by reducing the duration and severity of symptoms[40,41,42]. Consumption of lactic acid bacteria has also been shown to reduce the risk of developing a type of diarrhoea which commonly occurs as a result of antibiotic treatments.

\section{Allergies}

Studies have indicated an alteration in the composition of the gut microflora, such as decrease in the numbers of lactobacilli, preceding the development of an allergy. Probiotics have been shown to reduce the incidence of childhood eczema by half, compared to placebo, when administered during pregnancy and up to 6 months postnatally [43].The incidence of asthma or rhinitis was not altered. A follow-up study demonstrated a two-fold increase in transforming growth factor $b 2$, an antiinflammatory cytokine, in the breast milk of mothers receiving probiotics compared to placebo. Moreover, the reduction in risk of atopic eczema in children whose mothers received probiotics compared to placebo (15 versus $47 \%$ ) was still evident at 2 years [44].

Probiotics may exert a beneficial effect on allergic reaction by improving mucosal barrier function. In addition, probiotics consumption by young children may beneficially affect immune system development. Probiotics such as Lactobacillus GG may be helpful in alleviating some of the symptoms of food allergies such as those associated with milk protein [45]. Probiotics consumption may thus be a means for primary prevention of allergy in susceptible individuals. This could play a key role in minimizing allergy at a time when the prevalence of allergic disease in Western 
societies has increased dramatically over the past 40 years. Claims are made that probiotics strengthen the immune system to combat allergies, excessive alcohol intake, stress, exposure to toxic substances, and other diseases [46].

\section{Inflammatory bowel disease (IBD)}

Another potentially beneficial use for probiotics has been found to be in the treatment of Inflammatory Bowel Diseases (IBD), which include Chrohn's Disease (an inflammation of the small intestine), Ulcerative Colitis (an inflammation of the Colon resulting in ulceration) and pouchitis (an inflammation of the pouch created as treatment of a patient with ulcerative colitis).Researchers are unsure what causes the effects seen in Inflammatory Bowel Disease. Although some investigations have revealed that lactic acid bacteria such as Bifidobacteria sp. are particularly low in Chrohn's Disease patients, it has been suggested that rather than just a disruption to the normal microbes of the gut, this normal gut flora may actually cause an aggressive immunological response in IBD patients. Therefore it has been proposed that perhaps colonizing the gut with bacteria capable of favourably modulating this immunological response may be an effective strategy for preventing relapses in IBD patients [47].

\section{Necrotizing Enterocolitis (NEC)}

Necrotizing enterocolitis (NEC) is a life-threatening gastrointestinal disease seen most commonly in very low birth weight (VLBW) $(<1500 \mathrm{~g})$ infants. Factors contributing to the pathogenesis include immaturity of intestinal and immune function, enteral feeding, and gas-forming bacteria. In a randomized, controlled clinical trial in which 367 VLBW infants were fed prophylactically with either a probiotic combination of Lactobacillus acidophilus and infantis with breast milk or breast milk alone, the probiotics were associated with a significant reduction in incidence of NEC without significant adverse events [48]. Although mindful of theoretical risks of probiotics in premature babies, adverse events have not been a major problem and several commentators have acknowledged the importance of this and similar studies [49]. The results are consistent with earlier preliminary reports and with a subsequent controlled trial of a probiotic mixture (B infantis, Streptococcus thermophilus, and Bifidobacterium bifidus) in 145 VLBW neonates which showed that the probiotics were again associated with reduced incidence and severity of NEC [50].

Probiotics are a conceptually appealing approach to prevention of NEC; they appear to be safe and more effective than other strategies. There is also an argument for administering the probiotics to the mothers before delivery in addition to infants in conjunction with mother's milk [51]. Studies in VLBW infants treated with different probiotic preparations have universally demonstrated safety. Nonetheless, one must be cautious in the introduction of any new and living (potentially invasive) microorganism as therapy for immunologically immature VLBW infants.

\section{Antioxidant effects}

Free radicals are produced in the body in the course of regular metabolism but when exposed to xenobiotic agents from foods and environment the risk of radical production significantly increases. The most important are the free radicals derived

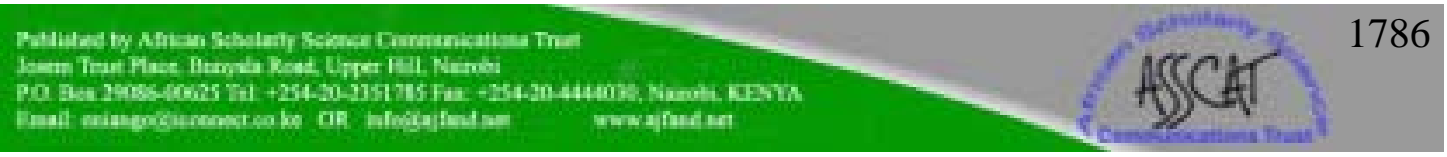


from oxygen. Provided the antioxidant system of the organism does not manage to neutralize them rapidly enough, they can cause destructive or lethal changes (such as apoptosis) through oxidation of membrane lipids, proteins, enzymes and DNA. The cellular and sub-cellular damage caused by free radicals plays an important role in the pathogenesis of cancer, cardiovascular diseases, allergies, atherosclerosis, and other civilization diseases [52]. The more extensive damage of the vital molecules in the brain through oxidation was detected also in patients with Alzheimer's disease [53].

The antioxidant defense mechanism in the body is composed not just of endogenous antioxidants but also of exogenous antioxidants from foods (vitamins $\mathrm{C}$ and $\mathrm{E}$, carotenoids, pholates, flavonoids, phytoestrogens and selenium). It has been found only recently that also the probiotic microorganisms can effectively trap reactive forms of oxygen. The experiment with vitamin E-deficient rats has revealed that the intracellular extract from Lactobacillus sp. recovers this deficiency [54]. The classical yoghurt bacteria Lactobacillus delbrueckii ssp. bulgaricus and Streptococcus thermophilus inhibit peroxidation of lipids through scavenging the reactive oxygen radicals, such as hydroxyl radical, or hydrogen peroxide [55].

The antioxidant activity of several species and strains of milk bacteria contained in fermented milk can significantly affect human health. This has been confirmed also by clinical studies of goat milk fermented with a starter culture Lactobacillus fermentum ME-3 [56]. The healthy volunteers have consumed for $21 \mathrm{~d}$ each day $150 \mathrm{~g}$ of milk, either sour or non-fermented. Sour milk compared to non-fermented milk has shown important improvement of the overall antioxidant activity of blood, as well as antioxidant status, prolonged resistance of lipoprotein fraction to oxidation, reduced level of peroxide lipoproteins and oxidized LDL cholesterol, reduced level of glutathione redox ratio, and increased overall antioxidant activity.

The anti-atherogenic activity of fermented milk may be the result of concerted action of several factors. Some lactobacilli produce antioxidant factors also in the human gastrointestinal tract [57]. The majority of milk bacteria show antioxidant behavior (eliminating the excess oxygen free radicals) producing superoxide dismutase, or glutathione. Taking this into account, several laboratories are working on the optional use of the milk bacteria in the form of food supplements that enhance also the antioxidant status of an individual [58]. The antioxidant activity exerts also various peptides derived from $\alpha$-lactalbumin, $\beta$-lactoglobulin and $\alpha$-casein [59].

\section{Minimum concentration of probiotic required for beneficial effect}

Information on recommend the minimum concentrations of probiotic bacteria for effective function is still insufficient. Nevertheless, adequate numbers of viable cells, namely the "therapeutic minimum" needs to be consumed regularly for transfer of the "probiotic" effect to consumers [60]. Consumption should be more than $100 \mathrm{~g}$ per day of bio-yogurt containing more than $10^{6} \mathrm{CFU} \mathrm{ml}{ }^{-1}$. Scientists suggest a minimum viable number of $10^{6} \mathrm{CFU} \mathrm{ml}{ }^{-1}$ or gram but recommend $10^{8} \mathrm{CFU} \mathrm{g}^{-1}$ to compensate for reduction through passage through the gut [61]. Yogurt is a classic example of a

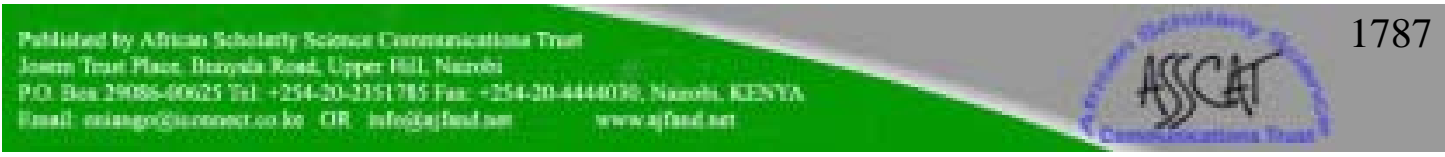


functional food with probiotics. Yogurt with probiotics, called bio-yogurt, should contain living bacterial cells. According to regulation, yogurt should contain $2 \times 10^{6}$ living bacteria in $1 \mathrm{ml}$ at the end of the recommended storage period. The daily dose of probiotic microorganisms should reach $1 \times 10^{9}$ cells.

The titre of bacteria in fermented drinks reaches $10^{8}$ to $10^{9} \mathrm{ml}^{-1}$ and decreases with storage. It is also possible to use tablets or capsules as additives to foodstuffs that contain lyophilized cultures of bacteria. The intake of functional dairy products also is more physiologically and more acceptable for patients or consumers as well. Within the last decade, consumers have made increasing reference to functional food, recognising the relationship between nutrition and health to the point of endowing an over reliance on pharmaceuticals and regarding prescription drugs as often being unnecessary, too expensive, unsafe and of dubious benefit once all the risks are considered [62].

\section{Safety of probiotics}

The safety of probiotics can be described as centuries of use fermented products; no reports of probiotic pathogens and safe use of active cultures in thousands of subjects have demonstrated that probiotic intake is safe. This past safe history is very important regarding use by pregnant woman and newborn, because there is some limitation for clinical trials. At the same time, some scientists have doubt about reasonability in taking a high dose of viable bacteria [63]. A review outlining the safety of current probiotic compounds has been published [64]. Cases of infection caused by Lactobacillus and Bifidobacteria are extremely rare. Previous research into the protective mechanisms associated with probiotic bacteria focused on the bacteriology of the gut and concentrated on intestinal colonisation and probioticinduced suppression of pathogen growth and/or invasion [65].

Indeed, the concept of a balance existing in the intestine, involving competition between probiotic and pathogenic bacteria for specific binding sites on intestinal epithelial cells has been well established in the literature. However, recent research has turned toward understanding the role of probiotics and their products and in enhancing and modulating innate and adaptive immune responses in the organism by other mechanisms [66].

\section{CONCLUSION}

The role of probiotics has expanded from use in gut health maintenance and supplementation in the event of dysbiosis (microfloral imbalance) during antibiotic therapy, to a wide range of health applications. With the increasing body of knowledge and research on known and emerging probiotic strains, future trends envisage their increased inclusion in dietary supplements and functional foods targeting diverse preventive health maintenance needs. Current innovations in functional foods with probiotics, including yogurts, beverages, bakery products, preserves, pickles, breakfast cereals, nutrition bars and other convenience products, 


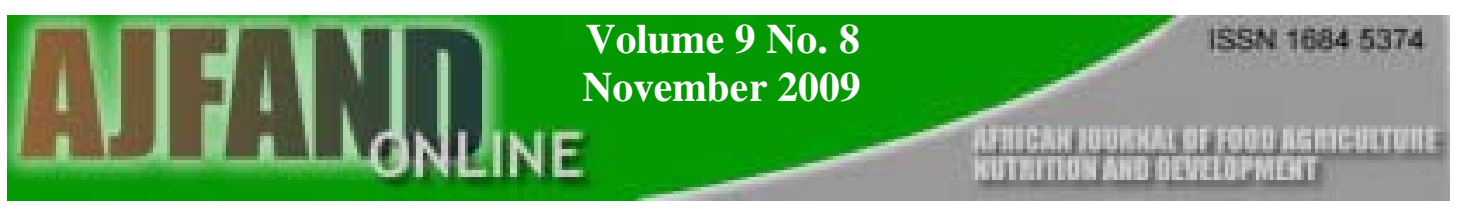

present attractive delivery options for these healthful ingredients. More research is needed on specific medicinal role of probiotics as a functional food or supplement as being useful in the management or prevention of certain acute and chronic diseases. There is need to establish the most effective dose and strains required for optimal benefit in each disease state, especially in those which either lack an adequate body of evidence in support of (such as the prevention of hypersensitivity diseases and respiratory tract infections), or that for which the evidence is not consistent, (such as lipid and blood pressure lowering). Consequently, far more research is needed before recommendations should be made that probiotics be used as a reliable method of treatment. 
Table 1: Proven probiotic strains

\begin{tabular}{|c|c|c|c|}
\hline Strain & Brand name & Producer & Country \\
\hline $\begin{array}{l}\text { Bacillus coagulans GBI-30, } \\
6086\end{array}$ & GanedenBC $^{30}$ & Ganeden Biotech & USA \\
\hline $\begin{array}{l}\text { Bifidobacterium animalis } \\
\text { subsp. lactis BB-12 }\end{array}$ & - & Chr. Hansen & Denmark \\
\hline $\begin{array}{l}\text { Bifidobacterium breve } \\
\text { Yakult }\end{array}$ & Bifiene & Yakult & Japan \\
\hline $\begin{array}{l}\text { Bifidobacterium infantis } \\
35624\end{array}$ & Align & Procter \& Gamble & $\begin{array}{l}\text { USA, } \\
\text { Canada }\end{array}$ \\
\hline $\begin{array}{l}\text { Bifidobacterium animalis } \\
\text { subsp. lactis HN019 (DR10) }\end{array}$ & Howaru Bifido & Danisco & Denmark \\
\hline $\begin{array}{l}\text { Bifidobacterium longum } \\
\text { BB536 }\end{array}$ & - & $\begin{array}{l}\text { Morinaga Milk } \\
\text { Industry }\end{array}$ & Japan \\
\hline Escherichia coli M-17 & ProBactrix & BioBalance & - \\
\hline Escherichia coli Nissle 1917 & Mutaflor & Ardeypharm & - \\
\hline $\begin{array}{l}\text { Lactobacillus acidophilus } \\
\text { DDS-1 }\end{array}$ & - & Nebraska Cultures & - \\
\hline $\begin{array}{l}\text { Lactobacillus acidophilus } \\
\text { LA-5 }\end{array}$ & - & Chr. Hansen & Denmark \\
\hline $\begin{array}{l}\text { Lactobacillus acidophilus } \\
\text { NCFM }\end{array}$ & - & Danisco & Denmark \\
\hline $\begin{array}{l}\text { Lactobacillus casei DN114- } \\
001\end{array}$ & Actimel/DanActive & Danone & France \\
\hline Lactobacillus casei CRL431 & - & Chr. Hansen & Denmark \\
\hline Lactobacillus casei F19 & Cultura & Arla Foods & Denmark \\
\hline Lactobacillus casei Shirota & Yakult & Yakult & Japan \\
\hline $\begin{array}{l}\text { Lactobacillus paracasei } \\
\text { St11 }\end{array}$ & Lactobacillus fortis & Nestlé & Switzerland \\
\hline Lactobacillus johnsonii La1 & - & Nestlé & Switzerland \\
\hline Lactococcus lactis L1A & - & Norrmejerier & - \\
\hline $\begin{array}{l}\text { Lactobacillus plantarum } \\
299 \mathrm{~V}\end{array}$ & $\begin{array}{l}\text { GoodBelly / } \\
\text { ProViva/ TuZen }\end{array}$ & $\begin{array}{l}\text { NextFoods Probi } \\
\text { Ferring }\end{array}$ & - \\
\hline $\begin{array}{l}\text { Lactobacillus reuteri ATTC } \\
55730\end{array}$ & - & BioGaia Biologics & - \\
\hline $\begin{array}{l}\text { Lactobacillus rhamnosus } \\
\text { ATCC } 53013\end{array}$ & Vifit and others & Valio & Finland \\
\hline $\begin{array}{l}\text { Lactobacillus rhamnosus } \\
\text { LB21 }\end{array}$ & Verum & Norrmejerier & - \\
\hline $\begin{array}{l}\text { Saccharomyces cerevisiae } \\
\text { (boulardii) lyo }\end{array}$ & DiarSafe and others & $\begin{array}{l}\text { Wren Laboratories } \\
\text { and others }\end{array}$ & - \\
\hline
\end{tabular}

- Not available, Sources [67]. 


\section{REFERENCES}

1. FAO/WHO. Health and Nutritional Properties of Probiotics in Food including Powder Milk with Live Lactic Acid Bacteria (2001). Report of a Joint FAO/WHO Expert Consultation on Evaluation of Health and Nutritional Properties of Probiotics in Food Including Powder Milk with Live Lactic Acid Bacteria.

http://www.who.int/foodsafety/publications/fs_management/probiotics/en/index .html

2. Metchnikoff E The Prolongation of Life, Putmans Sons, New York, 1908; 151183.

3. Gorbach SL Lactic acid bacteria and human health. Annals of Medicine. 1990; 22. $37-41$.

4. Berg RD The indigenous gastrointestinal microflora. Trends Microbiol. 1996; 4: 430-435.

5. Salminen S, Bouley $\mathbf{C}$ and MC Boutron-Ruault Functional food science and gastrointestinal physiology and function. Br J Nutr. 1998; 80: 147-171.

6. Hosoda M, Hashimoto H, Morita H, Chiba M and A Hosono Studies on antimutagenic effect of milk cultured with lactic acid bacteria on the Trp-P2induced mutagenicity to TA98 strain of Salmonella typhimuriumi. J. Dairy Res. 1992; 59: 543-549.

7. Renner $\mathbf{H W}$ and $\mathbf{R}$ Münzner The possible role of probiotics as dietary antimutagens. Mutat Res. 1991; 262: 239-245.

8. Orrhage K, Sillerström E, Gustafsson J J̈, Nord CE and J Rafter Binding of mutagenic heterocyclic amines by intestinal and lactic acid bacteria. Mutat Res. 1994; 311: 239-248.

9. Zhang XB and Y Ohta In vitro binding of mutagenic pyrolyzates to lactic acid bacterial cells in human gastric juice. J. Dairy Sci. 1991; 74: 752-757.

10. Hentges DJ Biotransformation of bile acids and cholesterol by the intestinal microflora. Human intestinal microflora in health and disease. New York: Academic Press (1983).

11. Mott GE, Moore RW, Redmond HE and R Reiser Lowering of serum cholesterol by intestinal bacteria in cholesterol-fed piglets. Lipids. 1973; 8: 428-431. 
12. Gilliland SE and ML Speck Deconjugation of bile acids by intestinal Lactobacilli. Appl. Environ Microbiol. 1977; 33:15-28.

13. Gilliland SE Health and nutritional benefits from lactic acid bacteria . FEMS Microbiol. Rev. 1990; 7: 175-188.

14. Schaafsma G, Meuling WJA, van Dokkum W and C Bouley Effects of a milk product, fermented by Lactobacillus acidophilus and with fructooligosaccharides added, on blood lipids in male volunteers . Eur. J. Clin. Nutr. 1998; 52: 436 -440.

15. de Roos NM, Schouten $G$ and MB Katan Yoghurt enriched with Lactobacillus acidophilus does not lower blood lipids in healthy men and women with normal to borderline high serum cholesterol levels. Eur. J. Clin. Nutr. 1998; 53: 277-280.

16. Pereira DI and GR Gibson Effects of consumption of probiotics and prebioticson serum lipid levels in humans. Crit Rev Biochem Mol Biol. 2002; 37:259-281.

17. Taranto MP, Medici M, Perdigon G, Ruíz Holgado AP and GF Valdez Effect of Lactobacillus reuteri on the prevention of hypercholesterolemia in mice. J Dairy Sci.2000; 83:401-403.

18. Nakamura Y, Yamamoto N, Sakai K and T Takano Antihypertensive effects of sour milk and peptides isolated from it that are inhibitors to angiotensin Iconverting enzyme. J. Dairy Sci .1995; 78: 1253-1257.

19. Yamamoto N, Maeno M and T Takano Purification and characterization of an antihypertensive peptide from a yogurt-like product fermented by Lactobacillus helveticus CPN4. J. Dairy Sci. 1999; 82:1388-1393.

20. Hata Y, Yamamoto M, Ohni M, Nakajima K, Nakamura Y and T Takano A placebo-controlled study of the effect of sour milk on blood pressure in hypertensive subjects . Am. J. Clin. Nutr. 1996; 64:767-771.

21. Perdigon G, Alvarez $\mathbf{S}$ and AP Holgado Immunoadjuvant activity of oral Lactobacillus casei: influence of dose on the secretory immune response and protective capacity in intestinal infections. J. Dairy Res. 1991; 58: 485-496.

22. Haacher GE and RS Lambrecht Augmentation of macrophage phagocytic activity by cell-free extracts of selected lactic acid-producing bacteria. J. Dairy Sci. 1993; 76: 2485-2492.

23. Arunachalam K, Gill HS and RK Chandra Enhancement of natural immune function by dietary consumption of Bifidobacterium lactis (HN019). Eur. J. Clin. Nutr. 2000; 54: 263-267. 
24. Felley $\mathbf{C}$ and $\mathbf{P}$ Michetti Probiotics and Helicobacter pylori. Best Pract. Res. Clin. Gastroenterol. 2003; 17: 785-91.

25. Oh Y, Osato MS, Han X, Bennett G and WK Hong Folk yoghurt kills Helicobacter pylori. J. Appl. Microbiol. 2002; 93: 1083-1088.

26. Sgouras D, Maragkoudakis P, Petraki K, Martinez-Gonzalez B, Eriotou E, Michopoulos S, Kalantzopoulos G, Tsakalidou E and A Mentis In vitro and in vivo inhibition of Helicobacter pylori by Lactobacillus casei strain Shirota. Appl. Environ. Microbiol. 2004; 70: 518-526.

27. Pinchuk IV, Bressollier P, Verneuil B, Fenet B, Sorokulova IB, Megraud F and MC Urdaci In vitro anti-Helicobacter pylori activity of the probiotic strain Bacillus subtilis 3 is due to secretion of antibiotics. Antimicrob. Agents Chemother. 2001; 45: 3156-3161.

28. Mukai T, Asasaka T, Sato E, Mori K, Matsumoto $M$ and $\mathbf{H}$ Ohori Inhibition of binding of Helicobacter pylori to the glycolipid receptors by probiotic Lactobacillus reuteri .FEMS Immunol. Med. Microbiol. 2002; 32: 105-110.

29. Pantoflickova D, Corthesy-Theulaz I, Dorta G, Stolte M, Isler P, Rochat F, Enslen $M$ and AL Blum Favourable effect of regular intake of fermented milk containing Lactobacillus johnsonii on Helicobacter pylori associated gastritis. Aliment Pharmacol. Ther.2003; 18: 805-813.

30. Felley CP, Corthesy-Theulaz I, Rivero JL, Sipponen P, Kaufmann M, Bauerfeind P, Wiesel PH, Brassart D, Pfeifer A, Blum AL and P Michetti Favourable effect of acidified milk (LC-1) on Helicobacter pylori gastritis in man. Eur. J. Gastroenterol. Hepatol. 2001; 13: 25-29.

31. Gotteland $\mathbf{M}$, Brunser $\mathbf{O}$ and $\mathbf{S}$ Cruchet Systematic review: are probiotics useful in controlling gastric colonization by Helicobacter pylori? Alimentary Pharmacology Therapeutics. 2006; 23(8):1077-1086.

32. Pantoflickova D, Corthesy-Therlaz I, Dorta G, Stolte M, Isler P, Rochat F, Enslen $M$ and AL Blum Favourable effect of regular intake of fermented milk containing Lactobacillus johnsonii on Helicobacter pylori associated gastritis. Alimentary Pharmacology \& Therapeutics. 2003; 18(8): 805-813

33. Sakamoto I, Igarashi M, Kimura K, Takagi A, Miwa T and Y Koga Suppressive effect of Lactobacillus gasseri OLL 2716 (LG21) on Helicobacter pylori infection in humans. The Journal of Antimicrobial Chemotherapy.2001; 47(5):709-710. 
34. Tursi A, Brandimarte G, Giorgetti GM and ME Modeo Effect of Lactobacillus casei supplementation on the effectiveness and tolerability of a new second-line 10-day quadruple therapy after failure of a first attempt to cure Helicobacter pylori infection. Med. Sci. Monit. 2004; 10: 662-666.

35. Shimbo I, Yamaguchi T, Odaka T, Nakajima K, Koide A, Koyama H and H Saisho Effect of Clostridium butyricum on fecal flora in Helicobacter pylori eradication therapy. World Journal of Gastroenterology. 2005; 11(47), 75207524.

36. Armuzzi A, Cremonini F and F Bartolozzi The effect of oral administration of Lactobacillus $G G$ on antibiotic-associated gastrointestinal side-effects during Helicobacter pylori eradication therapy. Aliment Pharmacol. Ther. 2001; 15: 163-169.

37. Canducci F , Armuzzi A, Cremonini F, Cammarota G, Bartolozzi F, Pola P, Gasbarrini G and A Gasbarrini A lyophilized and inactivated culture of Lactobacillus acidophilus increases Helicobacter pylori eradication rates. Aliment Pharmacol. Ther. 2000; 14: 1625-1629.

38 Myllyluoma E, Ahlroos T, Veijola L, Rautelin H, Tynkkynen S and $\mathbf{R}$ Korpela Effects of anti-Helicobacter pylori treatment and probiotic supplementation on intestinalmicrobiota. Int. J. Antimicrobiol. Agents. 2007; 29: $66-72$.

39. Parashar UD, Holman RC, Clarke MJ, Bresee JS and RI Glass Hospitalizations associated with rotavirus diarrhea in the United States, 1993 through 1995: surveillance based on the new ICD-9-CM rotavirus-specific diagnostic code. J. Infect. Dis. 1998; 177: 13 -17.

40. Guandalini S, Pensabene $\mathbf{L}$ and MA Zikri Lactobacillus $G G$ administered in oral rehydration solution to children with acute diarrhea: a multicenter European trial, J. Pediatr. Gastroenterol. Nutr. 2000; 30: 54 -60.

41. Shornikova AV, Casas IA, Isolauri E, Mykkanen $\mathbf{H}$ and $\mathbf{T}$ Vesikari Lactobacillus reuteri as a therapeutic agent in acute diarrhea in young children, J. Pediatr. Gastroenterol. Nutr. 1997; 24: 399 -404.

42. Chicoine $\mathbf{L}$ and $\mathbf{J H}$ Joncas Use of lactic enzymes in non-bacterial gastroenteritis, Union Med. Can. 1973; 102:1114-1115.

43. Kalliomaki M, Salminen S, Arvilommi H, Kero P, Koskinenp and E Isolauri Probiotics in primary prevention of atopic disease: A randomized placebo-controlled trial. Lancet. 2003; 361: 1869-1871. 
44. Rautavaara S, Kalliomaki $\mathbf{M}$ and $\mathbf{E}$ Isolauri Probiotics during pregnancy and breast-feeding might confer immunomodulatory protection against atopic disease in the infant. J. Allergy Clin. Immunol.2002; 109: 119-121.

45. Majamaa $\mathbf{H}$ and E Isolauri Probiotics: A novel approach in the management of food allergy. J. Allergy Clin. Immunol. 1997; 99: 179-185.

46. Nichols AW "Probiotics and athletic performance: A systematic review". Curr. Sports Medicine Reports .2007; 6: 269-273.

47. Schultz M and RB Sartor Probiotics and inflammatory bowel diseases. Am. J. Gastroenterol. 2000; 95: 19-26.

48. Lin HC, Su BH, Chen AC, Lin TW, Tsai CH, Yeh TF and W Oh Oral probiotics reduce the incidence and severity of necrotizing enterocolitis in very low birth weight infants. Pediatrics. 2005; 115: 1-4.

49. Kliegman RM Oral probiotics reduce the incidence and severity of necrotizing enterocolitis in very low birth weight infants. J. Pediatr. 2005; 146:710-714.

50. Bin-Nun A, Bromiker R, Wilschanski M, Kaplan M, Rudensky B, Caplan $\mathbf{M}$ and $\mathbf{C}$ Hammerman Oral probiotics prevent necrotizing enterocolitis in very low birth weight neonates. J. Pediatr.2005; 147:192-196.

51. Rinne M, Kalliomaki M, Arvilommi H, Salminen $\mathbf{S}$ and $\mathbf{E}$ Isolauri Effect of probiotics and breastfeeding on the bifidobacterium and lactobacillus/enterococcus microbiota and humoral immune responses. $J$. Pediatr. 2005; 147: 186-191.

52. Agerholm-Larsen L, Raben A, Haulrik N, Hansen AS, Manders M and A Astrup Effects of 8 weeks intake of probiotic milk products on risk factors for cardiovascular diseases. Eur.J.Clin.Nutr.2000; 54: 288-297.

53. Filipčík P, Cente M, Ferenčík M, Hulín I and M Novák The role of oxidative stress in the pathogenesis of Alzheimer's disease. Bratisl.Med.J.2006; 107: 384394.

54. Kaizu H, Sasaki $M$ and $\mathbf{H}$ Nakajima Effect of antioxidative lactic acid bacteria on rats fed a diet deficient in vitamin E. J.Dairy Sci.1993; 46: 24932499.

55. Ling MY and CL Yen Antioxidative ability of lactic acid bacteria. J.Agric.Food Chem.1999; 47:1460-1466.

56. Songisepp E, Kals J, Kullisaar T, Mändar R, Hutt P, Zilmer $\mathbf{M}$ and $\mathbf{M}$ Mikelsaar Evolution of the functional efficacy of an antioxidative probiotic in healthy volunteers. Nutr.J. 2005; 4: 22-31. 
57. Ljungh $\mathbf{A}$, Lan $\mathbf{J}$ and $\mathbf{N}$ Yanagisawa Isolation, selection and characteristics of Lactobacillus paracasei subsp. paracasei F16. Microb. Health Dis.2002; 3 (Suppl.): 4-6.

58. Songisepp E, Kullisaar T, Hutt $\mathbf{P}$, Elias $\mathbf{P}$, Brilene $\mathbf{T}$, Zilmer $\mathbf{M}$ and $\mathbf{M}$ Mikelsaar A new probiotic cheese with antioxidative and antimicrobial activity. J.Dairy Sci.2004; 87: 2013-2017.

59. Fitzgerald RK and BA Murray Bioactive peptides and lactic farmentations. Internat.J.Dairy Technol.2006; 59:118-125.

60. Raipulis J, Toma MM and P Semjonovs The effect of probiotics on the genotoxicity of furazolidone. Int. J. Food Microbiol. 2005; 102: 343-347.

61. Shah NP Effects of milk derived bioactives: an overview. Br. J. Nutr. 2000; 84: $3-10$.

62. Bagchi D Nutraceuticals and functional foods regulations in the United State and around the world. Toxicology. 2006; 221: 1-3.

63. Henriksson A, Borody $\mathbf{T}$ and $\mathbf{R}$ Clancy Probiotics under the regulatory microscope. Expert Opin. Drug safety. 2005; 4: 1135-1143.

64. Borriello SP, Hammes WP, Holzapfel W, Marteau P, Schrezenmeir J, Vaara $M$ and MA Brudnak Probiotics as adjuvant to detoxification protocols. Medical Hypothesis . 2002; 58: 382-385.

65. Clancy R Immunobiotics and the probiotic evolution. FEMS Immunol. Med. Microbiol. 2003; 22: 9-12.

66. Fedorak RN and KL Madsen Probiotics and prebiotics in gastrointestinal disorders. Curr. Opin. Gastroenterol. 2004; 20: 146-155.

67. Sanders ME Probiotics, strains matter. Functional foods \& nutraceuticals magazine. 2007; June: 36-41. 